ARTIGO

https: / /doi.org/10.22239/2317-269x.01596

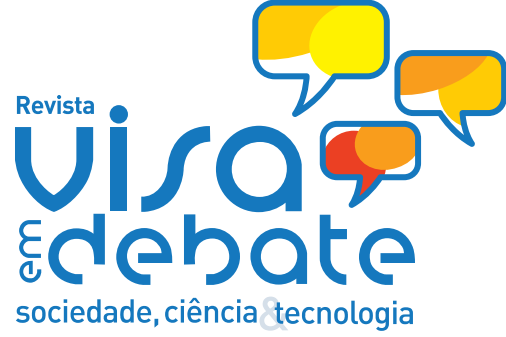

sociedade, ciência tecnologia

\title{
Fake news frente a pandemia de COVID-19
}

\section{Fake news in face of the COVID-19 pandemic}

Rafael Christian de Matos* (D)

Universidade Federal de Minas Gerais (UFMG), Belo Horizonte, MG, Brasil

\footnotetext{
* E-mail: rafaelchristiandm@gmail.com
}

Recebido: 10 maio 2020

Aprovado: 25 maio 2020

\section{RESUMO}

Introdução: A pandemia do novo coronavírus (SARS-CoV-2) no cenário brasileiro instaurou muitas incertezas e medos na população. Entretanto, outra adversária da saúde pública que surgiu sobre a temática foi a divulgação de fake news que dificultaram o enfrentamento da nova doença. Objetivo: Avaliar as fake news sobre o coronavírus divulgadas no programa "Saúde sem fake news" do Ministério da Saúde e traçar um perfil destas notícias. Método: A pesquisa de caráter descritivo avaliou o banco de dados "Saúde sem Fake news" do Ministério da Saúde. A busca de dados ocorreu entre os meses de janeiro e abril, e as notícias foram segmentadas em quatro grupos: "Produtos para saúde", "Notificações de casos", "Terapêutica" e "Informações sobre a COVID-19". Além disso, traçou-se a frequência de ocorrência de cada grupo no período analisado, avaliando os tipos de assinatura das notícias que circulam na mídia. Resultados: Foram encontradas 79 fake news, sendo que destas o maior grupo de notícias estava na segmentação "Terapêutica", que totalizou 34 ocorrências. 0 conteúdo deste grupo foi majoritariamente sobre o uso de bebidas quentes para prevenção e tratamento da COVID-19. Sobre a frequência de aparecimento das notícias, os grupos que estão aumentando em ocorrência são: "Terapêutica" e "Produtos para saúde". Com relação à assinatura das notícias, os remetentes são variáveis, porém ocorre um destaque para o elevado número de notícias assinadas por profissionais da saúde (16). Conclusões: As notícias sobre a COVID-19 devem ser avaliadas de forma crítica e deve-se atentar principalmente a notícias sobre terapêuticas e/ou veiculações assinadas por profissionais da área da saúde.

PALAVRAS-CHAVE: Sars-Cov-2; Fake News; Pandemia; Brasil

\section{ABSTRACT}

Introduction: The pandemic of the new coronavirus (SARS-CoV-2) in the Brazilian scenario has created many uncertainties and fears in the population. However, another opponent of public health has emerged on the topic: the dissemination of fake news, that made difficult coping with the disease. Objective: to evaluate the published fakes news about the coronavirus in the Ministry of Health's program named "Health without fake news" and to outline a profile of these news. Method: The descriptive research evaluated the "Health without fake news" database. The search for data occurred between January and April, and the news were segmented into four categories: Health products, Notifications of cases, Therapeutics and Information about COVID-19. In addition, the frequency of occurrence of each group in the analyzed period was traced, evaluating the subscription types of media circulations. Results: 79 fake news were found, of which the largest class of news was Therapeutics, with 34 occurrences. The content of this class was mostly about the use of hot drinks for prevention and treatment of COVID-19. Regarding the frequency of news appearance, the groups that have been increasing the number of occurrences are Therapeutics and Health products. With regard to news subscriptions, senders are variable, but there is an emphasis on the high number of news signed by health professionals (16). Conclusions: The news about COVID-19 should be critically evaluated and attention should be paid mainly to news about therapies and/or information signed by health professionals. 


\section{INTRODUÇÃO}

As notícias que propagam conteúdo não verdadeiros são comumente denominadas de fake news. Este termo, que é classificado de muitas formas, pode ser caracterizado como uma informação com baixo cunho racional, lógico ou verdadeiro, que entra em um fluxo constante de propagação $0^{1,2}$.

O compartilhamento deste conteúdo, que ocorre muitas vezes de forma desenfreada, é frequentemente estruturado em formato jornalístico e fornece um caráter de confiabilidade ao receptor desta mensagem. Dessa forma, o compartilhamento virtual em massa que se transforma em um contexto de propagação da desinformação vem se tornando um problema de saúde pública ${ }^{3,4}$.

Em janeiro de 2020, a Organização Mundial da Saúde (OMS) declarou que o surto de um novo tipo de coronavírus (SARS-CoV-2) era uma situação de "emergência de Saúde Pública de importância internacional". Dois meses depois, em março, a OMS declarou que a situação da doença havia se tornado uma situação de pandemia ${ }^{5}$.

O alarde social frente a doença, a qual pouco se conhecia, se instaurou rápido, gerando clima de incerteza e exacerbada insegurança por parte da população. Entretanto, além de ter que combater a pandemia, uma outra questão de ordem pública vigorou, que foi a propagação de especulações e de fake news por parte da população.

A grande questão que permeia a problemática da propagação de notícias falsas consiste no desnorteamento populacional, ocasionado pela incerteza de quais fontes podem ser confiáveis. Desta forma, notícias robustas e verdadeiras adquirem menor impacto em diversos núcleos sociais.

Além disso, a propagação de diversas notícias errôneas acerca do Sistema Único de Saúde (SUS) e da gestão do Ministério da Saúde (MS) pode propagar boatos que acabam deslegitimando as estruturas destas organizações. E, devido ao cenário político e econômico no qual o Brasil se insere, estas reverberações midiáticas podem ter elevado impacto em decisões futuras por parte da população.

O MS, com o intuito de combater as fake news nos meios midiáticos, criou um canal denominado "Saúde sem fake news", que objetiva a análise de notícias virais como verdadeiras ou como fakes. Para conseguir contemplar de forma mais específica a situação da COVID-19, gerou um canal específico para estas informações. Desta forma, a análise minuciosa destes conteúdos possibilita, com uma linguagem acessível, a propagação de informações verdadeiras e a diminuição da credibilidade de notícias falsas ${ }^{6}$.

\section{MÉTODO}

O estudo de caráter descritivo contou com a análise das notícias falsas sobre o coronavírus divulgadas na página "Saúde sem fake news" do MS. O período analisado foi entre os meses de janeiro e abril de 2020. Foram obtidas 79 notícias.
A pesquisa contou com a tabulação de todas as notícias falsas divulgadas no portal virtual em software Excel $2010 \AA$, categorizando-as em quatro grupos distintos. A categorização ocorreu por meio das informações presentes na notícia disponível no portal do MS, não tendo sido consultadas outras fontes.

O primeiro grupo de análise, denominado "Produtos para saúde”, engloba notícias falsas acerca de produtos correlatos, que são definidos pela Agência Nacional de Vigilância Sanitária (Anvisa) como: equipamento, aparelho, material, artigo ou sistema de uso ou aplicação médica, odontológica ou laboratorial, destinado à prevenção, diagnóstico, tratamento, reabilitação ou anticoncepção e que não utiliza meio farmacológico, imunológico ou metabólico para realizar sua principal função em seres humanos, podendo entretanto ser auxiliado em suas funções por tais meios ${ }^{7}$.

O segundo grupo, denominado "Notificações de casos de COVID-19", comporta notícias que retratem afirmações falsas acerca da notificação e da divulgação de dados epidemiológicos de novos casos de COVID-19. Além disso, engloba também notícias do perfil de disseminação da doença.

O terceiro grupo, "Terapêutica", aborda as notícias sobre métodos preventivos ou curativos. Foram incluídas notícias de cunho farmacológico ou não, que estiveram sob análise do banco de dados do MS.

A última categorização, denominada "Informações sobre a COVID-19", comportou as demais notícias acerca do tema. Dessa forma, foram abordadas temáticas sobre a origem e o curso da doença, sua sintomatologia, forma de disseminação e comportamento do vírus SARS-CoV-2.

Após segmentar as informações, foi definida a frequência de aparecimento em cada um dos grupos. Porém, a heterogeneidade das informações demandou que cada grupo fosse analisado e dividido de forma conveniente.

Além disso, traçou-se a frequência de ocorrência de cada um dos grupos ao longo do tempo analisado, com a finalidade de se estabelecer um perfil de distribuição das notícias circuladas ao longo do tempo.

Por fim, as 79 notícias foram reclassificadas de acordo com a autoria da notícia em oito grupos: não assinadas; assinadas por profissionais; assinadas por entidades federais ou de saúde; referenciando ações de outros países; referenciando pesquisas científicas; assinadas por outras entidades jurídicas; assinadas por internautas e notícias sem autoria definida (não tiveram sua divulgação no site do MS, o que impossibilitou visualizar a autoria).

\section{RESULTADOS E DISCUSSÃO}

Ao se visitar a página virtual do MS, que avalia notícias da área da saúde veiculadas nos meios midiáticos como verdadeiras ou fakes, foi possível elencar 84 notícias que abordavam a temática 
do coronavírus. Destas, apenas cinco (6\%) foram classificadas como verdadeiras, demonstrando o número alarmante de notícias falsas que são veiculadas para a população.

Um dos problemas mais notórios dessas notícias falsas, veiculadas em meios de comunicação de fácil acesso, é a banalização do conteúdo que abordam. No decorrer do compartilhamento e com a visualização repetida das temáticas debatidas nas notícias falsas, o indivíduo adquire a tendência de banalizar o que tem sido dito. Desta forma, ao diminuir seu senso crítico frente a estas notícias, acaba aceitando-as como verdadeiras ${ }^{8}$.

Este problema se torna ainda mais significativo, uma vez que, frente a pandemia, certas atitudes errôneas podem comprometer amplamente a saúde coletiva. Dessa forma, gera-se perda da eficácia de medidas preventivas (como o afastamento social) e/ ou são gerados falsos alardes ou falsas esperanças para o leitor.

Entretanto, um grande obstáculo a ser enfrentado frente as fake news do coronavírus é a diversidade de enquadramentos que estes conteúdos assumem. Esta dificuldade de delineamento de perfil das notícias quando contornado pode ser utilizada com o objetivo de alertar a população sobre formas de diferenciar as notícias falsas das notícias verdadeiras.

Ao segmentar as fake news em quatro grupos, pode-se obter um número de notícias igual a quatro para "Produtos para saúde", 17 para "Notificações de casos", 34 sobre "Terapêutica" e 24 para
“Informações sobre o COVID-19". A distribuição da frequência destas notícias em função da sua distribuição ao longo dos meses de janeiro a maio pode ser visualizada na Figura 1.

Observa-se que, entre os grupos, o que apresentou uma frequência mais constante ao longo dos meses, foi o de "Terapêutica". Provavelmente isto associa-se com a esperança populacional do aparecimento de um processo terapêutico que consiga ser eficaz de forma preventiva ou corretiva para a doença. Desta forma, este ímpeto de desejo de segurança impulsiona os indivíduos ao excesso do compartilhamento destes dados.

Percebe-se também que em abril ocorreu redução das notícias falsas sobre as informações e as notificações da COVID-19. Embora não se possa precisar a justificativa para tal, pode-se suspeitar que isto se deva a ampla divulgação pelo MS de dados acerca da situação epidemiológica, juntamente com dados informativos confiáveis à população, demonstrando não apenas a eficácia desta prática, como também a necessidade de sua continuidade.

Com relação ao grupo "Produtos para saúde", insumos esses que têm se tornado grandes aliados à prevenção da disseminação da doença por diversos protocolos clínicos e legisações ${ }^{9}, 10,11,12,13,14,15,16,17$, embora seu quantitativo não seja majoritário, o seu impacto é relevante. Isso, pois, no descrédito populacional do efeito destes, a contaminação dos indivíduos pode ser ainda maior. A segmentação por parte desses produtos pode ser visualizada na Tabela 1.

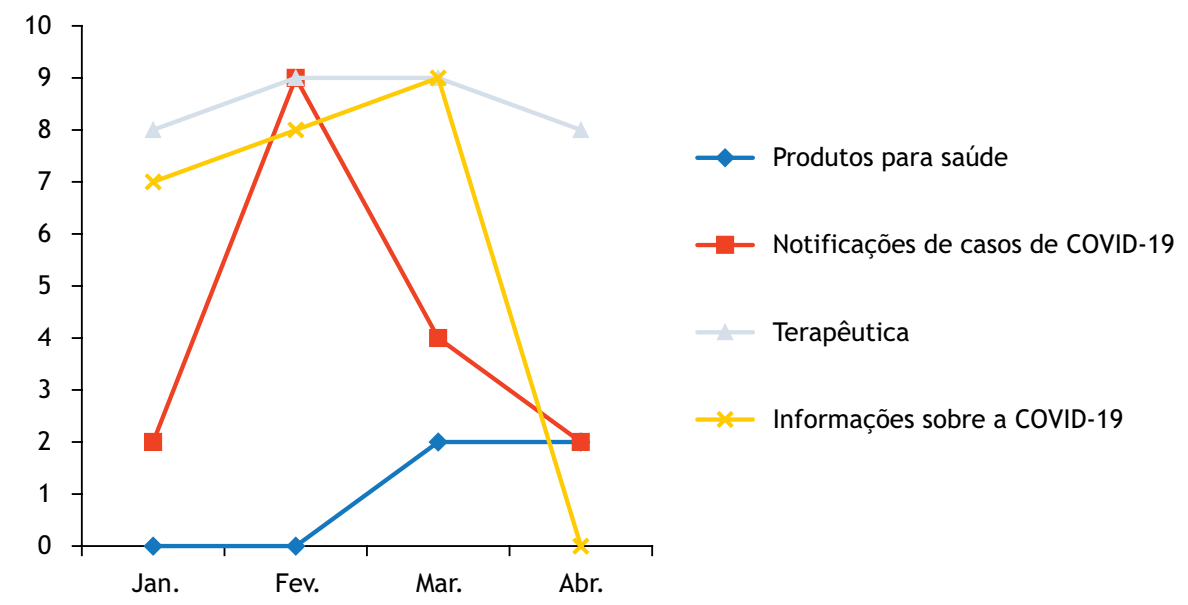

Fonte: Elaborada pelos autores, 2020.

Figura 1. Frequência da ocorrência de fake news no período de janeiro a abril de acordo com a categorização em grupos.

Tabela 1. Categorização de fake news sobre o grupo "Produtos para saúde"

\begin{tabular}{|c|c|c|c|}
\hline Categoria & $\begin{array}{l}\text { Número de } \\
\text { notícias }\end{array}$ & Produto & Títulos das notícias \\
\hline \multirow{3}{*}{ Produtos para saúde } & \multirow{3}{*}{4} & Máscara & $\begin{array}{l}\text { “Máscaras sem qualidade distribuídas pelo Ministério da Saúde” } \\
\text { “Máscaras de doação da China são contaminadas com coronavírus” }\end{array}$ \\
\hline & & & “Álcool em gel é a mesma coisa que nada" \\
\hline & & Álcool em gel & $\begin{array}{c}\text { "Utilizar álcool em gel nas mãos para prevenir coronavírus altera bafômetro } \\
\text { nas blitz" }\end{array}$ \\
\hline
\end{tabular}

Fonte: Elaborada pelos autores, 2020. 
Percebe-se a gravidade destas quatro notícias, uma vez que todas desincentivam o uso de máscaras ou de álcool gel para higienizar as mãos, seja por sua ineficácia ou por levantar hipóteses de danos ao usuário. Outro fator que precisa ser explicitado, é que notícias que difamam o MS, acabam desvalorizando o SUS. Dessa forma, muitas questões políticas envolvendo este sistema são demonstradas, como a notícia de baixa qualidade de máscaras fornecidas pelo $\mathrm{MS}^{18}$.

Entretanto, confrontando a notícia de baixa qualidade das máscaras, a página de fake news do MS adverte que o produto demonstrado no vídeo apresentava máscaras diferentes das adquiridas pelo órgão ${ }^{19}$.

Ao pensar na possibilidade de propagação da doença devido a fake news, encontrou-se outro entrave, visto que até mesmo as notificações de caso de COVID-19 configuram-se como um grupo de bombardeamento de notícias não verdadeiras. Os dados com relação a este grupo podem ser visualizados na Tabela 2 .

Observa-se que a principal classe de notícias apresentada foi o "Aparecimento do $1^{\circ}$ caso em regiões". Entretanto, é notório que esta e as demais notícias falsas, de forma generalizada, seriam evitadas caso fossem visitadas fontes de confiança do SUS, como os relatórios do MS e os pronunciamentos do ministro da saúde para rede nacional.

Além disso, considerando o papel do SUS na realização de exames diagnóstico, tem-se novamente uma depreciação deste sistema. 0 SUS não apenas se estrutura e se prepara para o enfrentamento de diversas doenças transmissíveis ${ }^{20}$, como atua de forma ativa e resistente para interromper a transmissão, melhorar o diagnóstico e ser habilitado no tratamento dos casos específicos de COVID-1921.

A depreciação do SUS é retratada de forma explícita na classe "Registros de notificações" que contém uma única notícia de nome "Software das Unidades de Pronto Atendimento (UPA) obrigam registro de coronavírus". O conteúdo dessa fake news reporta que enfermeiras de algumas UPA alegam que pacientes com sintomatologias diferentes da causada pelo SARS-CoV-2 precisam ser cadastrados como se tivessem os sintomas característicos da doença ${ }^{22}$.

O caráter depreciativo abordado, além de demonstrar déficit da atenção básica, indica que o número de pacientes com sintomatologia do coronavírus está superestimado. Desta forma, a população pode desacreditar na seriedade da propagação da doença reduzindo as medidas restritivas e dessa forma pode aumentar o número de contaminados.

Entretanto, observa-se que, ao mesmo tempo que o número de pessoas portadoras do SARS-CoV-2 é alvo de grande número de notícias falsas, observamos que o principal grupo de notícias que foram cadastradas no banco de dados analisado foi sobre a terapêutica para o novo coronavírus. Isto ocorreu, possivelmente, devido ao grande alarde social associado à esperança por um método preventivo eficiente ou uma medida corretiva eficaz, fazendo com que estas notícias possuam grande poder de alastramento. As principais categorizações sobre o grupo "Terapêuticas" foram levantadas e podem ser visualizadas na Tabela 3.

São notórios a relevância e o grande número de veiculações midiáticas acerca do tema, fazendo com que a temática da terapêutica perpasse por dois tópicos principais. 0 primeiro e mais eminente é observado devido a elevada porcentagem de notícias que envolvem bebidas quentes (37\%), como chás medicinais. 0 conhecimento tradicional popular, que se utiliza destes recursos para alívios de sintomas de resfriados e gripes convencionais, tem se expandido ao novo vírus. Entretanto, nenhuma comprovação deste recurso terapêutico foi demonstrada, pois como é informado pelo MS: "Até o momento, não há nenhum medicamento, substância, vitamina, alimento específico ou vacina que possa prevenir a infecção pelo coronavírus (COVID-19)"23.

0 segundo fato, embora represente apenas 3\% das notícias abordadas pelo banco de fake news do MS, mas é de elevado impacto social, é a indicação do uso dos medicamentos cloroquina e hidroxicloroquina, como tratamento eficaz ao coronavírus. A criticidade do tema, emerge a partir do momento que esta notícia serve de incentivador da população em adquirir e utilizar os fármacos. Frente a demanda abusiva populacional do medicamento nas farmácias e drogarias, os medicamentos cloroquina e hidroxicloroquina estiveram escassos ao público que demanda o seu uso contínuo para outras doenças, como lúpus eritematoso sistêmico, artrite reumatoide e malária ${ }^{24,25}$.

Além disso, notícias foram veiculadas afirmando que o Food and Drug Administration (FDA) havia permitido o uso destes

Tabela 2. Categorização de fake news sobre o grupo "Notificações de casos de COVID-19".

\begin{tabular}{|c|c|c|c|}
\hline Categoria & $\begin{array}{c}\text { Número de } \\
\text { notícias }\end{array}$ & Classe & $N(\%)$ \\
\hline \multirow{7}{*}{ Notificações de casos } & \multirow{7}{*}{17} & Registro de notificações & $1(6)$ \\
\hline & & Dados epidemiológicos & $4(24)$ \\
\hline & & Aparecimento do $1^{\circ}$ caso em regiões & $6(35)$ \\
\hline & & Subnotificações por parte do governo & $1(6)$ \\
\hline & & Imigrantes com a doença em território nacional & $2(12)$ \\
\hline & & Estimativa sobre o "pico" da doença & $1(6)$ \\
\hline & & Notícia não disponível na íntegra para avaliação & $2(12)$ \\
\hline
\end{tabular}

Fonte: Elaborada pelos autores, 2020. 
medicamentos. Porém, em sua nota à imprensa, o FDA afirmou que apenas existiam estudos em andamento para averiguar a eficácia dos medicamentos ${ }^{24,26}$.

Frente a este comportamento social, com o objetivo de garantir a exclusividade na aquisição pelos pacientes que realmente necessitem utilizar essa medicação, a Anvisa publicou a Resolução de Diretoria Colegiada (RDC) $n^{\circ} 351^{27}$, de 20 de março de 2020, que classificou a cloroquina e a hidroxicloroquina na lista C1, configurando-as nas listas de substâncias de controle especial. Sendo assim, para adquiri-las o paciente precisa apresentar receita em duas vias, uma ficará retida no estabelecimento farmacêutico e a outra permanecerá de posse do paciente.
Ademais, este fenômeno adquire ainda mais a perspectiva de saúde coletiva, ao se observar que estes medicamentos possuem efeitos adversos severos e muitas vezes letais como toxicidade ocular, cardiotoxicidade e distúrbios sanguíneos. Além disso, o intervalo terapêutico destas substâncias é muito curto, ou seja, dosagens pouco maiores do que a terapêutica apresentam elevadas chances de gerarem efeitos adversos e elevado grau de toxicidade ${ }^{24}$.

Outrossim, o problema com a divulgação de notícias acerca da COVID-19, também dificultam a credibilidade das informações confiáveis que são divulgadas. Como demonstrado na Tabela 4 muitas especulações acerca do curso da doença e do

Tabela 3. Categorização de fake news sobre o grupo "Terapêutica" para COVID-19.

\begin{tabular}{|c|c|c|c|c|c|}
\hline Categoria & $\begin{array}{l}\text { Número de } \\
\text { notícias }\end{array}$ & Finalidade & Classe de tratamento & Subclasse & $N(\%)$ \\
\hline \multirow{17}{*}{ Terapêutica } & \multirow{17}{*}{34} & \multirow{7}{*}{ Prevenção } & \multirow{2}{*}{ Farmacológica } & Vacina & $2(6)$ \\
\hline & & & & Vitaminas & $1(3)$ \\
\hline & & & \multirow{4}{*}{ Não farmacológica } & Bebidas quentes & $4(11)$ \\
\hline & & & & Alimentos & $1(3)$ \\
\hline & & & & Vitaminas & $3(9)$ \\
\hline & & & & Bebidas alcóolicas & $1(3)$ \\
\hline & & & $\begin{array}{l}\text { Notícia não disponível na } \\
\text { íntegra para avaliação }\end{array}$ & Não encontrado & $1(3)$ \\
\hline & & \multirow{9}{*}{ Tratamento } & \multirow{4}{*}{ Farmacológica } & Medicamento para piolhos & $1(3)$ \\
\hline & & & & Cloroquina/Hidroxicloroquina & $1(3)$ \\
\hline & & & & Antirretrovirais & $2(6)$ \\
\hline & & & & Não especificado & $2(6)$ \\
\hline & & & \multirow{4}{*}{ Não farmacológica } & Bebidas quentes & $9(26)$ \\
\hline & & & & Alimentos & $1(3)$ \\
\hline & & & & Água & $1(3)$ \\
\hline & & & & Óleos & $1(3)$ \\
\hline & & & $\begin{array}{l}\text { Notícia não disponível na } \\
\text { íntegra para avaliação }\end{array}$ & Não encontrado & $2(6)$ \\
\hline & & Não especificado & $\begin{array}{l}\text { Notícia não disponível na } \\
\text { íntegra para avaliação }\end{array}$ & Não encontrado & $1(3)$ \\
\hline
\end{tabular}

Fonte: Elaborada pelos autores, 2020.

Tabela 4. Categorização de fake news de "Informações sobre a COVID-19".

\begin{tabular}{|c|c|c|c|}
\hline Categoria & $\begin{array}{l}\text { Número de } \\
\text { notícias }\end{array}$ & Classe & $\mathrm{N}(\%)$ \\
\hline \multirow{8}{*}{$\begin{array}{l}\text { Informações sobre o } \\
\text { COVID-19 }\end{array}$} & \multirow{8}{*}{24} & Origem da doença & $4(16)$ \\
\hline & & Aplicativo do governo brasileiro acerca da COVID-19 & $1(4)$ \\
\hline & & China e o enfrentamento ao coronavírus & $5(21)$ \\
\hline & & Informes do Ministério da Saúde & $3(13)$ \\
\hline & & Carnaval e a propagação do coronavírus & $2(8)$ \\
\hline & & Efeitos, sintomas e sequelas da doença & $3(13)$ \\
\hline & & Condições de permanência do vírus em sua forma viável & $2(8)$ \\
\hline & & Outros & $4(17)$ \\
\hline
\end{tabular}

Fonte: Elaborada pelos autores, 2020. 
comportamento do vírus são geradas. Embora este grupo de fake news apresente elevada frequência entre as notícias do banco de dados, a sua distribuição homogênea dificulta elencar o perfil destas notícias baseadas em suas classes de segmentação. Desta forma se torna dificultoso alertar a população de um possível cunho de inverdade de novas notícias que podem vir a circular.

É possível visualizar tons de especulação em torno da origem da construção das mensagens que tangem a origem da doença. Além disso, é muito presente o som alarmista frente a divulgação de notícias que envolvem o enfrentamento e o desdobramento da China frente a pandemia, servindo de indicativos de pouca veracidade no conteúdo apresentado.

As notícias muitas vezes alarmistas e exageradas, como "Tribunal chinês para matar 20 mil pacientes com coronavírus", além de gerar uma especulação de um possível quadro futuro do curso da doença no Brasil, ainda ocasiona em uma deturpação do país asiático que tange questões políticas e econômicas ${ }^{28}$. Sendo assim, uma boa ferramenta a ser utilizada como forma de detecção de fake news como sugerido na justificativa do MS é observar notícias com tom alarmista, com informações vagas e com erros ortográficos, como ocorreu com este conteúdo citado.

Além disso, é notório como nos demais casos há depreciação do SUS, tanto nas notícias que deturpam ou inventam informes do MS, quanto na notícia "Aplicativo Coronavírus-SUS, do Governo do Brasil, é inseguro", que relata que o aplicativo do governo não respeita a segurança e a privacidade do usuário. Desta forma, embora não desqualifiquem a informação divulgada pelo programa, desincentivam a utilização do recurso confiável que pode ser utilizado de forma acessível pela maioria da população ${ }^{29}$.
Mas também, um outro recurso que pode ser utilizado para delinear o perfil das fake news é a observação do tipo de assinatura que acompanha a mensagem. Com esta finalidade foi elaborada a Figura 2, que compila os tipos de assinaturas presentes nas notícias e os segmentos por classe de dados. É nítido observar que a maior frequência de assinatura no banco de dados analisado é por profissionais da saúde, fazendo com que notícias que tenham essa espécie de remetente devam ser analisadas de forma crítica.

Entretanto, a ampla distribuição dos dados, que oscilam entre a ausência de assinaturas e o nome de órgãos oficiais, demonstra que sempre será necessário averiguar o conteúdo em fonte confiável. Uma boa maneira de se conseguir o engajamento populacional na procura de fontes confiáveis é a realização de divulgação de boletins científicos com linguagem acessível e dinâmica, para que esta espécie de conteúdo consiga chegar a todas as pessoas, de diferentes nichos sociais.

\section{CONCLUSÕES}

A ocorrência de fake news, embora muito presente nos meios midiáticos, segue alguns padrões, como linguajar alarmista, exagerado e divulgação com erros de português. Com o banco de dados do MS, observou-se que o maior número de notícias falsas englobou o grupo "Terapêutica" acerca do coronavírus, principalmente com a subclasse "bebidas quentes".

Além disso, segundo as projeções realizadas, as notícias sobre "Produtos para saúde" e "Terapêutica" tendem a se manter ou aumentar nos próximos meses. Contraposto a isso, os grupos "Notificações de casos" e "Informações sobre a COVID-19" tendem a se reduzir.

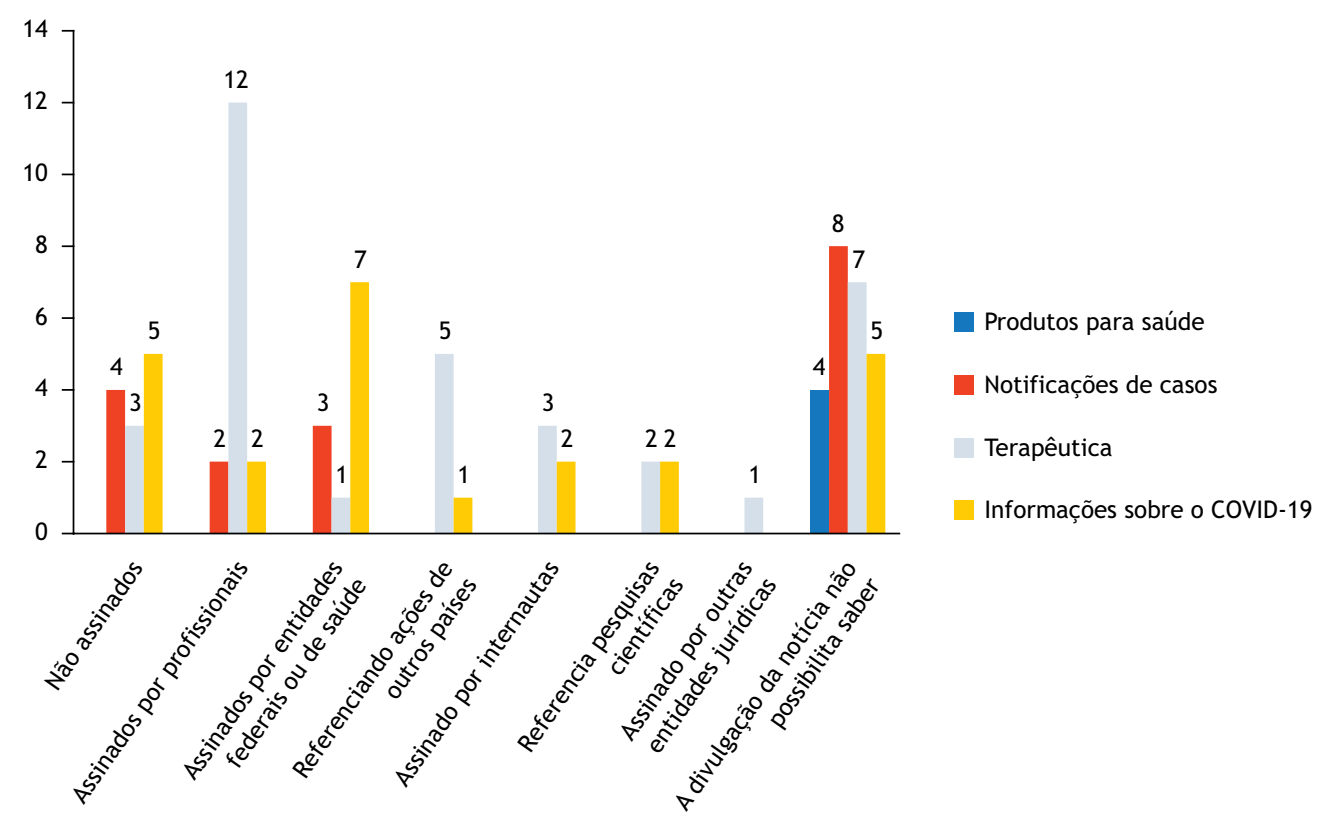

Fonte: Elaborada pelos autores, 2020.

Figura 2. Perfil de distribuição de assinaturas por grupo de notícias. 
A maior frequência de assinaturas dos conteúdos que estavam disponíveis para leitura foi por profissionais de saúde. Entretanto, o amplo espectro de identificações de remetentes destes conteúdos inviabiliza definir um perfil característico deste conteúdo.
Por fim, uma forte estratégia para diminuir a propagação de fake news é a viabilização do conteúdo científico confiável a população. Para tal, deveriam ser disponibilizados documentos acessíveis e dinâmicos que atraíssem os diversos grupos sociais, ajudando assim, na redução da propagação advertida de notícias falsas.

\section{REFERÊNCIAS}

1. Observatório da Comunicação - Obercon. As fake news numa sociedade pós-verdade: contextualização, potenciais soluções e análise. Lisboa: Observatório da Comunicação; 2018[acesso 1 maio 2020]. Disponível em: https://obercom.pt/wp-content/uploads/2018/06/2018Relatorios-Obercom-Fake-News.pdf

2. Carvalgo GACL, Kanffer GGB. 0 tratamento jurídico das notícias falsas (fake news). São Paulo: Consultor Jurídico; 2018[acesso 11 out 2019]. Disponível em: https://www.conjur.com.br/dl/tratamentojuridico-noticias-falsas.pdf

3. Monari ACP, Bertolli Filho C. Saúde sem fake news: estudo e caracterização das informações falsas divulgadas no canal de informação e checagem de fake news do Ministério da Saúde. Midia Cot. 2019;13(1):160-77. https://doi.org/10.22409/ppgmc.v13i1.27618

4. Lazer DMJ, Baum MA, Benkler Y, Berinsky AJ, Greenhill KM, Menczer F et al. The science of fake news. Science. 2018;359(6380):1094-6. https://doi.org/10.1126/science.aao2998

5. Representação da Organização Pan Americana de Saúde no Brasil - OPAS Brasil. COVID-19 (doença causada pelo novo coronavírus). Folha Informativa. 8 maio 2020[acesso 2 maio 2020]. Disponível em: https: / / www.paho.org/bra/index.php?option=com content\&view $=$ article\&id $=6101$ : covid19\&ltemid $=875$

6. Ministério da Saúde (BR). Saúde sem fake news. Brasília: Ministério da Saúde; 2020[acesso 2 maio 2020]. Disponível em: https://www.saude.gov.br/fakenews

7. Agência Nacional de Vigilância Sanitária - Anvisa. Resolução RDC № 185, de 22 de outubro de 2001. Aprova o regulamento técnico que trata do registro, alteração, revalidação e cancelamento do registro de produtos médicos na agência nacional de vigilância sanitária (Anvisa), e dá outras providências. Diário Oficial União. 24 out 2001.

8. Rocha BA, Lavarda SL, Silveira AM. O avanço das fake news e sua retratação na mídia de referência. In: Anais do $19^{\circ}$ Congresso de Ciências da Comunicação na Região Sul; Cascavel, Brasil. São Paulo: Sociedade Brasileira de Estudos Interdisciplinares da Comunicação; 2018.

9. Ministério da Saúde (BR). Nota técnica $N^{\circ} 9$, de 23 de março de 2020. Recomendações da coordenaçãogeral de atenção hospitalar e domiciliar em relação à atuação dos serviços de atenção domiciliar (SAD), programa melhor em casa na pandemia do coronavírus (COVID-19). Diário Oficial União. 24 mar 2020.
10. Ministério da Saúde (BR). Guia de vigilância epidemiológica: emergência de saúde pública de importância nacional pela doença pelo coronavírus 2019. Brasília: Ministério da Saúde; 2020[acesso 3 maio 2020]. Disponível em: https: / /www. conasems.org.br/wp-content/uploads/2020/03/guia_de_ vigilancia_2020.pdf

11. Ministério da Saúde (BR). Protocolo de manejo clínico do coronavírus (COVID-19) na atenção primária à saúde. Brasília: Ministério da Saúde; 2020[acesso 3 maio 2020]. Disponível em: https://www.conasems.org.br/wp-content/ uploads/2020/03/20200330_Pro tocoloManejo_ver06_Final.pdf

12. Ministério da Saúde (BR). Procedimento operacional padronizado: equipamento de proteção individual e segurança no trabalho para profissionais de saúde da APS no atendimento às pessoas com suspeita ou infecção pelo novo coronavírus (COVID-19): versão 2. Brasília: Ministério da Saúde; 2020[acesso 3 maio 2020]. Disponível em: https://www.conasems.org.br/wp-content/ uploads/2020/03/20200330_POP_EPI_ver002_Final.pdf

13. Ministério da Saúde (BR). Atendimento odontológico no SUS. Brasília: Ministério da Saúde; 2020[acesso 4 maio 2020]. Disponível em: http://189.28.128.100/dab/docs/ portaldab/documentos/COVID_19_ATENDIMENTO\%20 ODONTOLOGICO_SUS_APS_20200319_ver001.pdf

14. Ministério da Saúde (BR). Prevenção ao COVID-19 no âmbito das equipes de consultórios na rua. Brasília: Ministério da Saúde; 2020[acesso 4 maio 2020]. Disponível em: http://189.28.128.100/dab/docs/portaldab/documentos/ Consultorios_rua_APS_20200319_ver001.pdf

15. Ministério da Saúde (BR). Recomendações para adequação das ações dos agentes comunitários de saúde frente à atual situação epidemiológica referente ao COVID-19: versão 2 . Brasília: Ministério da Saúde; 2020[acesso 4 maio 2020]. Disponível em: https: / /www.conasems.org.br/wp-content/ uploads/2020/04/20200403_recomendacoes_ACS_COVID19_ ver002_final_b.pdf

16. Ministério da Saúde (BR). Nota técnica $N^{\circ} 7$, de 8 de abril de 2020. Trata das orientações a serem adotadas na atenção à saúde das gestantes no contexto da pandemia do novo coronavírus (SARS-CoV-2). Diário Oficial União. 9 abr 2020.

17. Ministério da Saúde (BR). Nota técnica $N^{\circ} 6$, de 23 de abril de 2020. Atenção à saúde do recém-nascido no contexto da infecção do novo coronavírus (SARS-CoV-2). Diário Oficial União. 24 abr 2020.

18. Neto M, Gomes TO, Porto FR, Rafael RMR, Fonseca MHS, Nascimento J. Fake news no cenário da pandemia de COVID-19. Cogitare Enferm. 2020;25:1-7. https://doi.org/10.5380/ce.v25i0.72627 
19. Ministério da Saúde (BR). Máscaras sem qualidade distribuídas pelo ministério da saúde e fake news. Saúde sem Fake News. 24 abr 2020[acesso 5 maio 2020]. Disponível em: https://www.saude.gov.br/fakenews/46779mascaras-sem-qualidade-distribuidas-pelo-ministerio-dasaude-e-fake-news

20. Teixeira MG, Costa MCN, Paixão ES, Carmo EH, Barreto FR, Penna GO. Conquistas do SUS no enfrentamento das doenças transmissíveis. Cienc Saude Coletiva. 2018;23(6):1819-28. https: / / doi.org/10.1590/1413-81232018236.08402018

21. Ministério da Saúde (BR). Protocolo $N^{\circ} 8$, de 1 de dezembro de 2011. Institui as diretrizes da política nacional de promoção da saúde do trabalhador do sistema único de saúde SUS. Diário Oficial União. 2 dez 2011.

22. Ministério da Saúde (BR). Software das UPA's obrigam registro de coronavirus. Saúde sem Fake News. $24 \mathrm{abr}$ 2020[acesso 5 maio 2020]. Disponível em: https: / /www. saude.gov.br/fakenews/46778-software-das-upas-obrigamregistro-de-coronavirus-e-fake-news

23. Ministério da Saúde (BR). Chá de limão com bicarbonato quente cura coronavirus. Saúde sem Fake News. 3 abr 2020[acesso 5 maio 2020]. Disponível em: https://www.saude.gov.br/fakenews/46652-cha-de-limaocom-bicarbonato-quente-cura-coronavirus-e-fake-news

24. Fundação Oswaldo Cruz - Fiocruz. Orientações sobre o uso da cloroquina para tratamento de pacientes infectados com SARS-CoV-2, agente etiológico da COVID-19. Rio de Janeiro: Fundação Oswaldo Cruz; 2020[acesso 5 maio 2020]. Disponível em: https://portal.fiocruz.br/sites/ portal.fiocruz.br/files/documentos/orientacoes_sobre_a_ cloroquina_nota_tecnica_.pdf
25. Agência Nacional de Vigilância Sanitária - Anvisa. Nota técnica sobre cloroquina e hidroxicloroquina. Brasília: Agência Nacional de Vigilância Sanitária; 2020[acesso 5 maio 2020]. Disponível em: http://portal. anvisa.gov.br/documents/219201/4340788/N ota+Te\% 25C2\%25B4cnica+sobre+Cloroquina+e +Hidroxicloroquina. pdf/659d0105-60cf-4cab-b80a-fa0e29e2e799

26. US Food \& Drugs Administration - FDA. Coronavirus (COVID-19) update: FDA continues to facilitate development of treatments. FDA News Release. 19 mar 2020[acesso 5 maio 2020]. Disponível em: https://www.fda.gov/newsevents/press-announcements/coronavirus-covid-19-updatefda-continues-facilitate-development-treatments

27. Agência Nacional de Vigilância Sanitária - Anvisa. Resolução RDC N 351, de 20 de março de 2020. Dispõe sobre a atualização do Anexo I (Listas de Substâncias Entorpecentes, Psicotrópicas, Precursoras e Outras sob Controle Especial) da Portaria SVS/MS n ${ }^{\circ} 344$, de 12 de maio de 1998, e dá outras providências. Diário Oficial União. 20 mar 2020.

28. Ministério da Saúde (BR). Tribunal chinês para matar 20 mil pacientes com coronavirus. Saúde sem Fake News. 27 fev 2020[acesso 6 maio 2020]. Disponível em: https: / / www.saude.gov.br/fakenews/46439-tribunalchines-para-matar-20-mil-pacientes-com-coronavirus-efake-news

29. Ministério da Saúde (BR). Aplicativo do coronavirus do SUS do governo do Brasil é inseguro. Saúde sem Fake News. 27 fev 2020[acesso 6 maio 2020]. Disponível em: https://www. saude.gov.br/fakenews/46586-aplicativo-coronavirus-susdo-governo-do-brasil-e-inseguro-e-fake-news

Contribuição dos Autores

Matos RC - Concepção, planejamento (desenho do estudo), aquisição, análise, interpretação dos dados e redação do trabalho. 0 autor aprovou a versão final do trabalho.

Conflito de Interesse

Os autores informam não haver qualquer potencial conflito de interesse com pares e instituições, políticos ou financeiros deste estudo.

Esta publicação está sob a licença Creative Commons Atribuição 3.0 não Adaptada.

Para ver uma cópia desta licença, visite http://creativecommons.org/licenses/by/3.0/deed.pt_BR. 